Supporting Information

\title{
Specially-Made Lipid-based Assemblies for Improving Transmembrane Gene Delivery: Comparison of Basic Amino Acid Residues-Rich Periphery
}

Qian Jiang ${ }^{1}$, Dong Yue ${ }^{1}$, Yu Nie ${ }^{*}, 1$, Xianghui Xu ${ }^{1}$, Yiyan $\mathrm{He}^{1}$, Shiyong Zhang ${ }^{1}$, Ernst Wagner $^{2}$, Zhongwei Gu*,1

1 National Engineering Research Center for Biomaterials, Sichuan University, Chengdu 610064, Sichuan, P. R. China

2 Center for Drug Research, Department of Pharmacy, Pharmaceutical

Biology-Biotechnology, and Center for NanoScience (CeNS),

Ludwig-Maximilians-Universitat, Butenandtstr. 5-13, D-81377. Munich, Germany. 
A
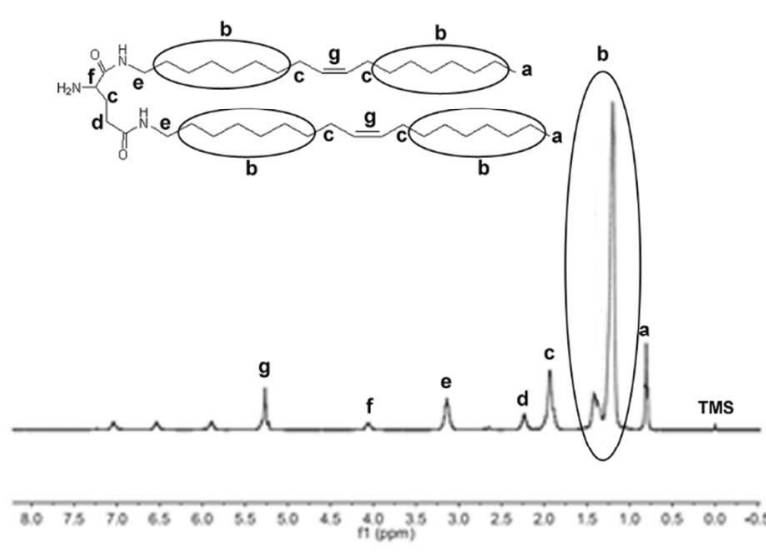

C

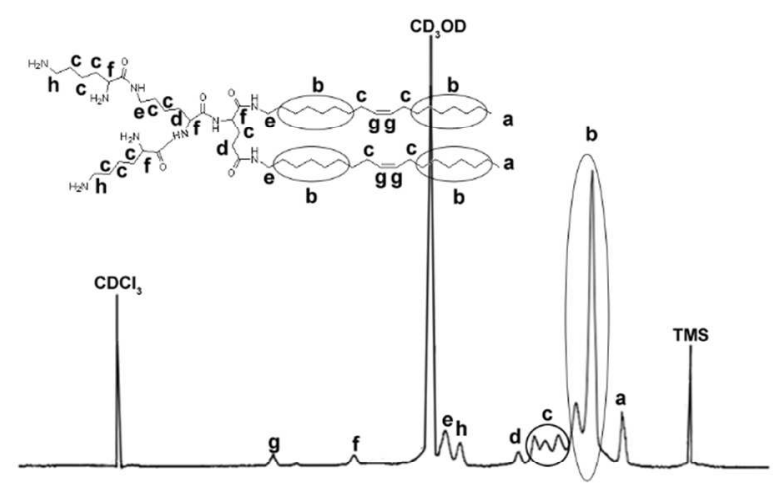

\begin{tabular}{lllllllllllllllllllll}
\hline 8.5 & 8.0 & 7.5 & 7.0 & 6.5 & 6.0 & 5.5 & 5.0 & 4.5 & 4.0 & 3.5 & 1.0 & 2.5 & 2.0 & 1.5 & 1.0 & 0.5 & 0.0 & 1
\end{tabular}

\section{E}

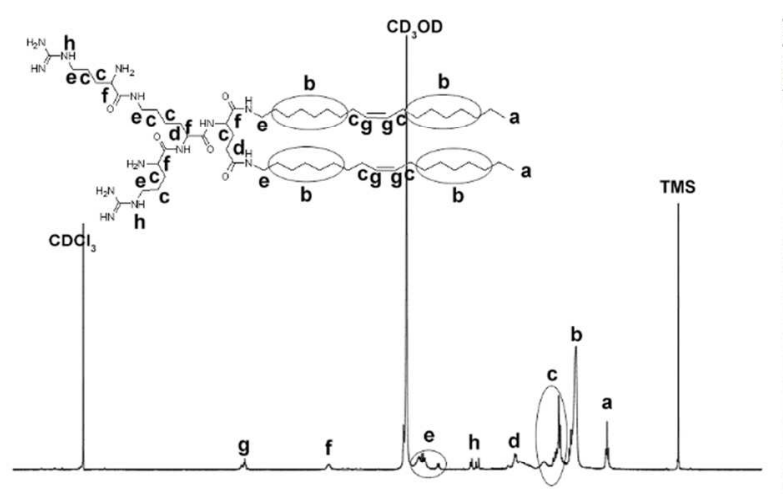

\begin{tabular}{lllllllllllllllllllll}
\hline 8.0 & 7.5 & 7.0 & 6.5 & 6.0 & 5.5 & 5.0 & 4.5 & 4.0 & $\begin{array}{l}3 \\
\mathrm{f}(\mathrm{ppm})\end{array}$ & 3.0 & 2.5 & 2.0 & 1.5 & 1.0 & 0.5 & 0.0 & -0.5
\end{tabular}

\section{B}

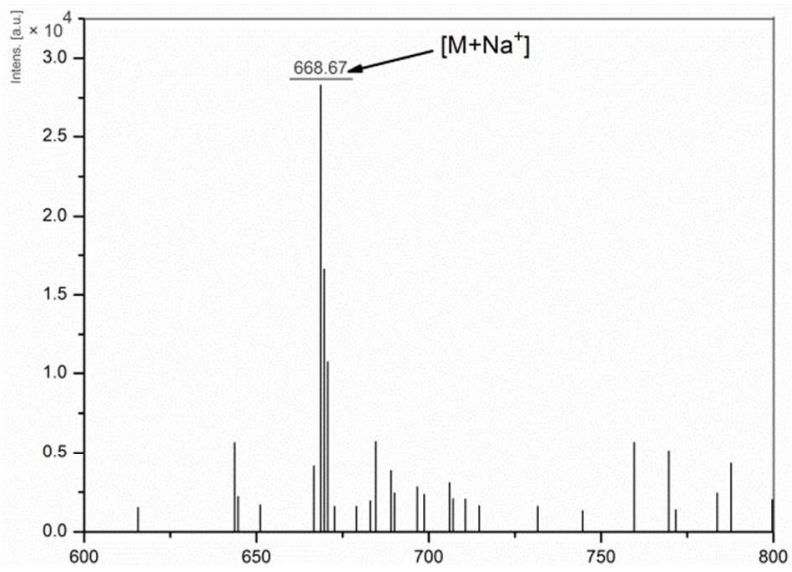

D

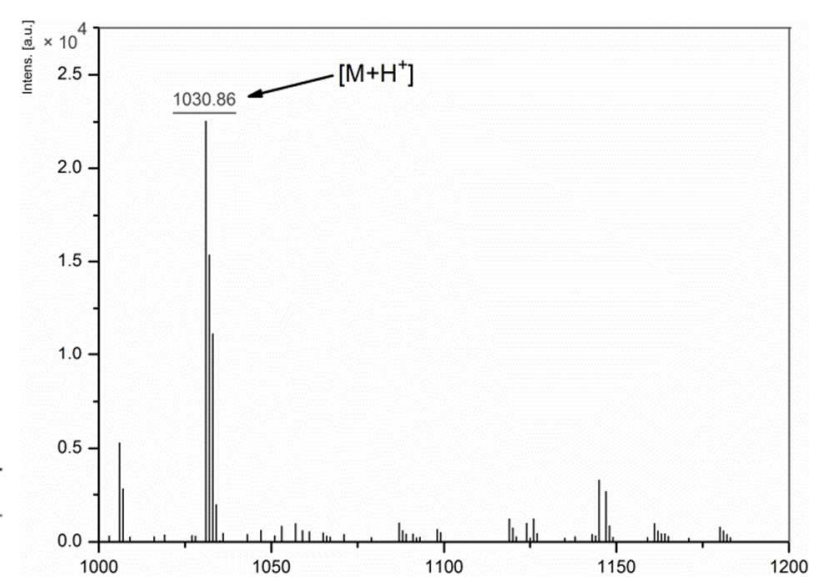

F

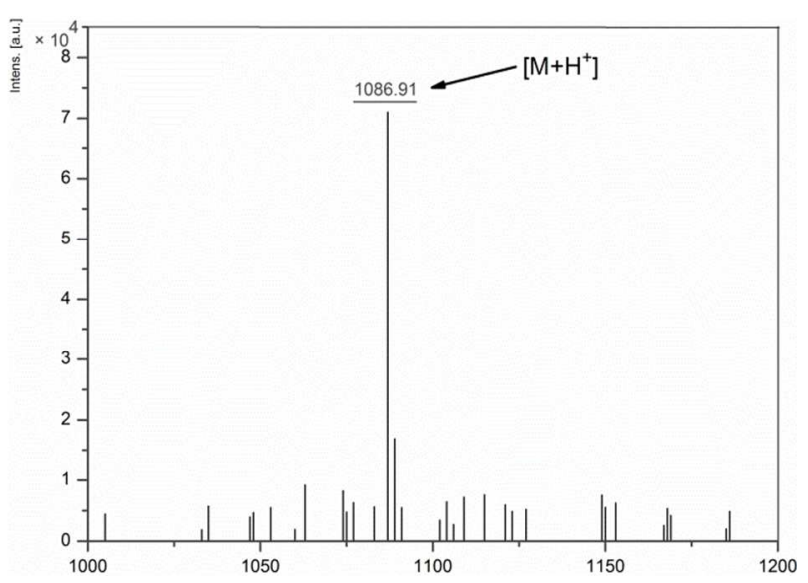



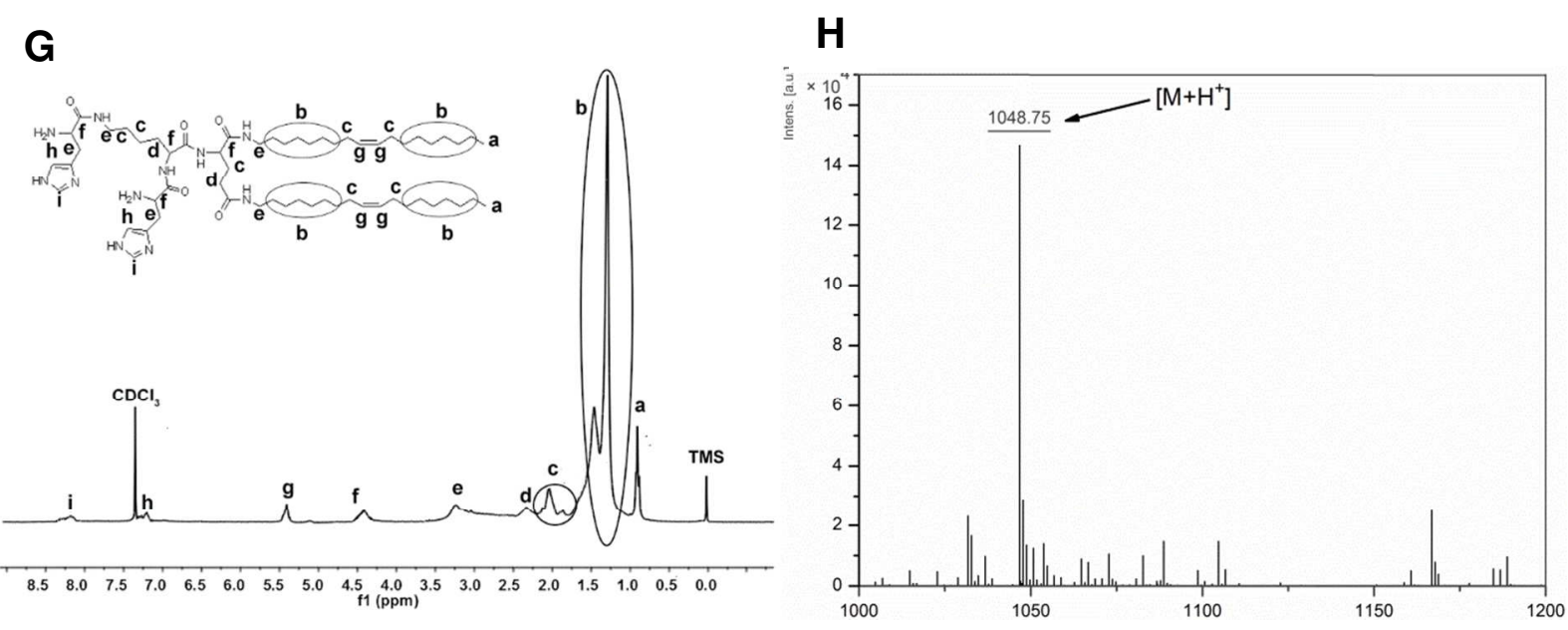

Figure S1. Chemical characterization $\left({ }^{1} \mathrm{H}-\mathrm{NMR}\right.$ spectrum and ESI-MS) of dendritic amino acid-modified cationic lipids.

(A) ${ }^{1} \mathrm{H}$ NMR of Compound $2\left(\mathrm{CDCl}_{3}, \mathrm{ppm}\right): 0.79\left(6 \mathrm{H},-\mathrm{CH}_{2} \mathrm{CH}_{3}\right), 1.20-1.46(48 \mathrm{H}$,

$-\mathrm{CH}_{2} \mathrm{CH}_{2 \text {-(stearyl) }),} 1.94 \quad\left(10 \mathrm{H}, \quad-\mathrm{CH}_{2} \mathrm{CH}=\mathrm{CH}-, \quad-\mathrm{CHCH}_{2}\right.$-(glutamate) $), \quad 2.24 \quad(2 \mathrm{H}$,

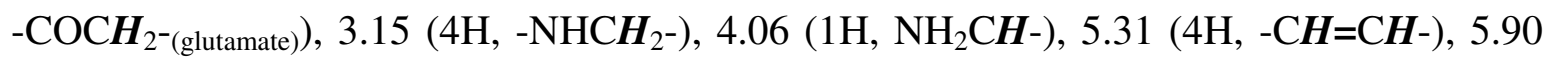
$\left(2 \mathrm{H},-\mathrm{COCHNH}_{2}\right), 6.54\left(1 \mathrm{H},-\mathrm{CH}_{2} \mathrm{CONH}-\right), 7.04(1 \mathrm{H},-\mathrm{CHCONH}-)$. (B) MS (ESI) of Compound 2: $\left[\mathrm{M}+\mathrm{Na}^{+}\right]=668.67$. (C) ${ }^{1} \mathrm{H}$ NMR of $\mathrm{KL}\left(\mathrm{CDCl}_{3}: \mathrm{CD}_{3} \mathrm{OD} 10: 1, \mathrm{ppm}\right)$ of : $0.88 \quad\left(6 \mathrm{H}, \quad-\mathrm{CH}_{2} \mathrm{CH}_{3}\right), \quad 1.27-1.43 \quad\left(48 \mathrm{H}, \quad-\mathrm{CH}_{2} \mathrm{CH}_{2}\right.$-(stearyl) $), \quad 1.70-1.99 \quad(26 \mathrm{H}$, - $\mathrm{NHCH}_{2} \mathrm{CH}_{2} \mathrm{CH}_{2-\text {-(lysine), }} \quad \mathrm{NH}_{2} \mathrm{CH}_{2} \mathrm{CH}_{2} \mathrm{CH}_{2} \mathrm{CH}_{2}$-(lysine), $\quad-\mathrm{CHCH}_{2} \mathrm{CH}_{2 \text {-(glutamic), }}$ $\left.-\mathrm{CH}_{2} \mathrm{CH}=\mathrm{CHCH}_{2}-\right), 2.24\left(4 \mathrm{H},-\mathrm{NHCH}_{2} \mathrm{CH}_{2} \mathrm{CH}_{2} \mathrm{CH}_{2}\right.$-(lysine), $\left.-\mathrm{CHCH}_{2} \mathrm{CH}_{2^{-} \text {(glutamic) }}\right) 2.96$ (4H, $\left.\mathrm{NH}_{2} \mathrm{CH}_{2}-\right), 3.14\left(6 \mathrm{H},-\mathrm{NHCH}_{2}-\right), 4.32$ (4H, -NHCOCH-), 5.33 ( 4H, -CH=CH-). (D) MS (ESI) of $\mathrm{KL}:\left[\mathrm{M}+\mathrm{H}^{+}\right]=1031.86 . \quad(\mathrm{E}){ }^{1} \mathrm{H}$ NMR of $\mathrm{RL}\left(\mathrm{CDCl}_{3}: \mathrm{CD}_{3} \mathrm{OD} 10: 1, \mathrm{ppm}\right): 0.88$ $\left(6 \mathrm{H}, \quad-\mathrm{CH}_{2} \mathrm{CH}_{3}\right), \quad 1.26-1.45 \quad\left(48 \mathrm{H},-\mathrm{CH}_{2} \mathrm{CH}_{2}\right.$-(stearyl) $), \quad 1.47-1.65 \quad(22 \mathrm{H}$, - $\mathrm{NHCH}_{2} \mathrm{CH}_{2} \mathrm{CH}_{2}$-(lysine), $\quad-\mathrm{NHCH}_{2} \mathrm{CH}_{2} \mathrm{CH}_{2}$-(arginine), $\quad-\mathrm{NHCHCH}_{2}$-(glutamic), $\left.-\mathrm{CH}_{2} \mathrm{CH}=\mathrm{CHCH}_{2^{-}}\right), \quad 2.00 \quad\left(4 \mathrm{H}, \quad-\mathrm{NHCHCH}_{2} \mathrm{CH}_{2^{-} \text {(glutamic) }}, \quad-\mathrm{NHCHCH}_{2^{-} \text {(lysine) }}\right), \quad 2.46$ 
$(2 \mathrm{H},-\mathrm{NHCNH}-), 2.95,3.14\left(10 \mathrm{H},-\mathrm{NHCH}_{2}-\right), 4.29(4 \mathrm{H},-\mathrm{NHCOCH}-), 5.34(4 \mathrm{H}$, $-\mathrm{C} \boldsymbol{H}=\mathrm{CH}-)$. (F) MS (ESI) of RL: $\left[\mathrm{M}+\mathrm{H}^{+}\right]=1086.91 .(\mathrm{G}){ }^{1} \mathrm{H}$ NMR of $\mathrm{HL}\left(\mathrm{CDCl}_{3}, \mathrm{ppm}\right)$ : $0.88 \quad\left(6 \mathrm{H}, \quad-\mathrm{CH}_{2} \mathrm{CH}_{3}\right), \quad 1.25-1.42 \quad\left(48 \mathrm{H}, \quad-\mathrm{CH}_{2} \mathrm{CH}_{2}\right.$-(stearyl) $), \quad 1.99 \quad(14 \mathrm{H}$, $-\mathrm{NHCH}_{2} \mathrm{CH}_{2} \mathrm{CH}_{2-\text {-(lysine) }}, \quad-\mathrm{NHCHCH}_{2}$-(glutamic), $\quad-\mathrm{CH}_{2} \mathrm{CH}=\mathrm{CHCH}_{2}$-), $2.30 \quad(4 \mathrm{H}$, $-\mathrm{CH}_{2} \mathrm{CO}$-(glutamic), $-\mathrm{CH}_{2} \mathrm{CH}$-(lysine) $), 2.95-3.18\left(10 \mathrm{H},-\mathrm{NHCH}_{2}-,-\mathrm{CCH}_{2}\right.$-(histidine) $), 4.35(4 \mathrm{H}$, -NHCOCH-), $5.33(4 \mathrm{H},-\mathrm{C} \boldsymbol{H}=\mathrm{C} \boldsymbol{H}-), 7.12(2 \mathrm{H},-\mathrm{CC} \boldsymbol{H}-), 8.09(2 \mathrm{H},-\mathrm{NC} \boldsymbol{H}-)$. (H) MS (ESI) of $\mathrm{HL}:\left[\mathrm{M}+\mathrm{H}^{+}\right]=1048.75$. 


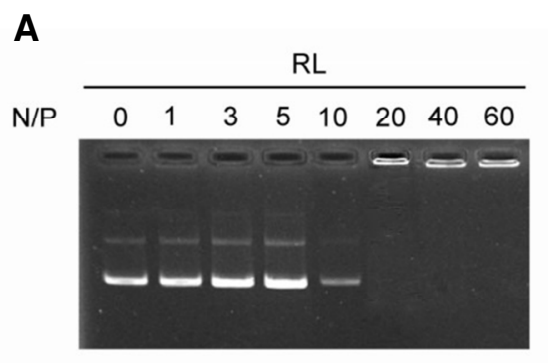

B

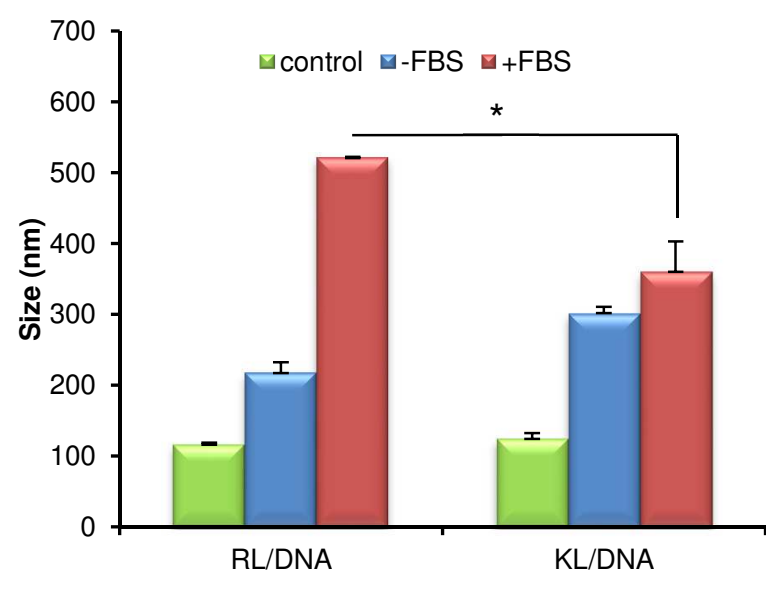

$\mathrm{KL}$

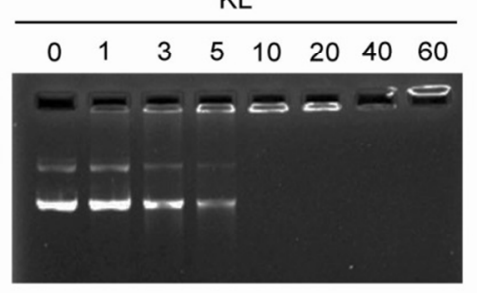

C
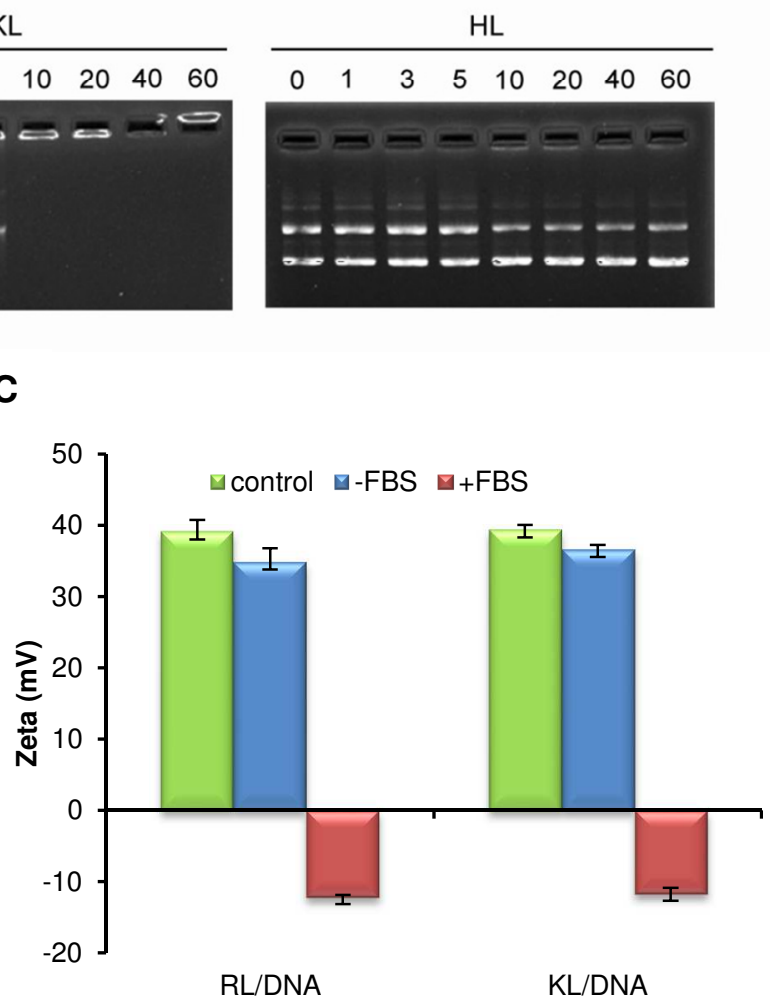

Figure S2. (A) Gel retardation assay of lipid-based assemblies/DNA complexes at different N/P ratios. (B) Size distribution and (C) zeta potential of the DNA complexes in DMEM with or without $20 \%$ FBS. Control group means the size and zeta potential of lipid-based assemblies/DNA complexes were measured in HBG buffering solution. All complexes were mixed with DNA at N/P ratio of $40 .(* p<0.05)$. 


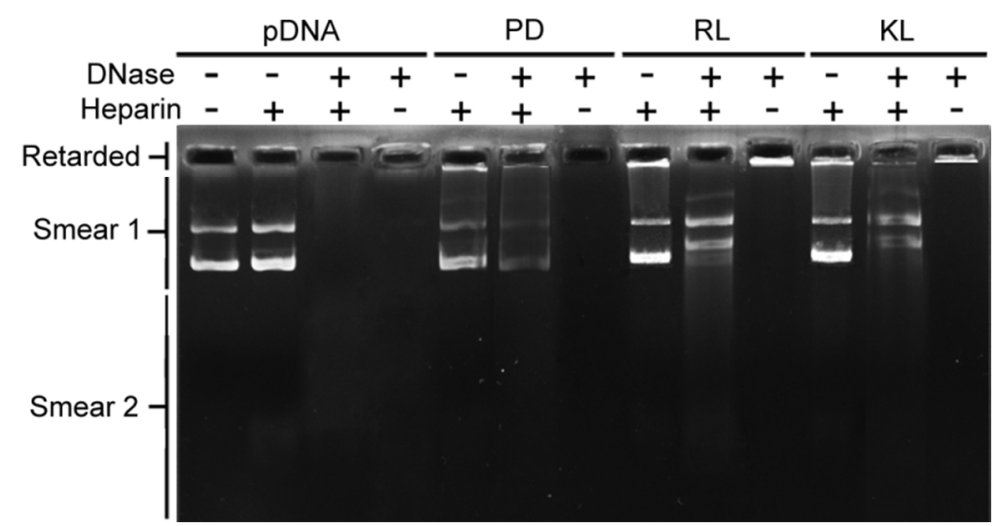

Figure S3. Agarose gel electrophoresis of indicated complexes incubated with DNase and/or heparin. PEI/DNA complexes were fabricated at N/P ratio of 10 , while RL (or KL)/DNA complexes were formed at N/P ratio of 40 . 


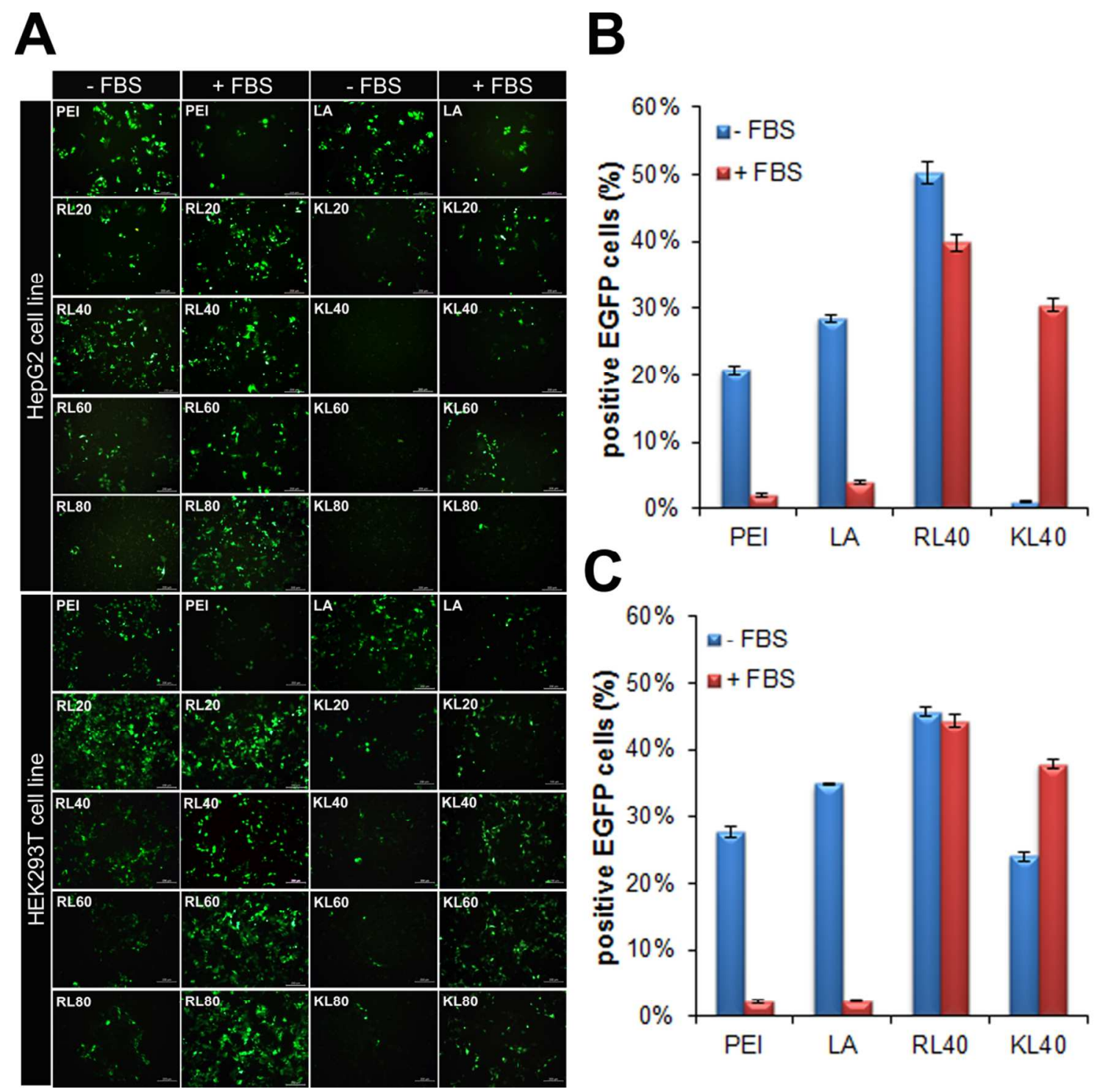

Figure S4. EGFP transfection effects with and without serum in HepG2 and HEK293T cells.

Prior to transfection, cells were treated with DMEM in the absent or present of $10 \%$ serum.

(A) Image of cells treated with arginine- and lysine-containing complexes were mixed with EGFP plasmid at different N/P ratios of 20-80. Quantitative study of EGFP transfection efficacies in HepG2 cells (B) and HEK293T cells (C). 


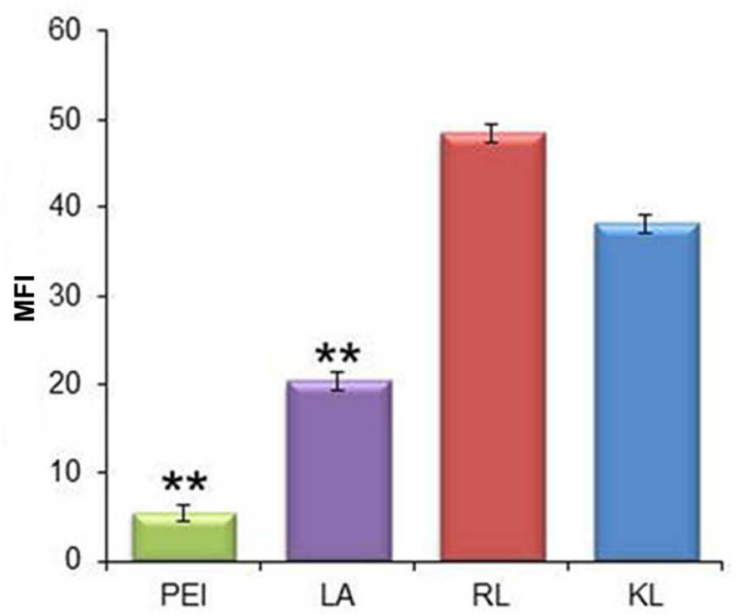

Figure S5. The mean fluorescent intensity (MFI) value of internalized complexes after HepG2 cells were treated with different complexes containing Cy5-labbeled DNA for 4 h. $* * p<0.01$ vs RL or KL group. 


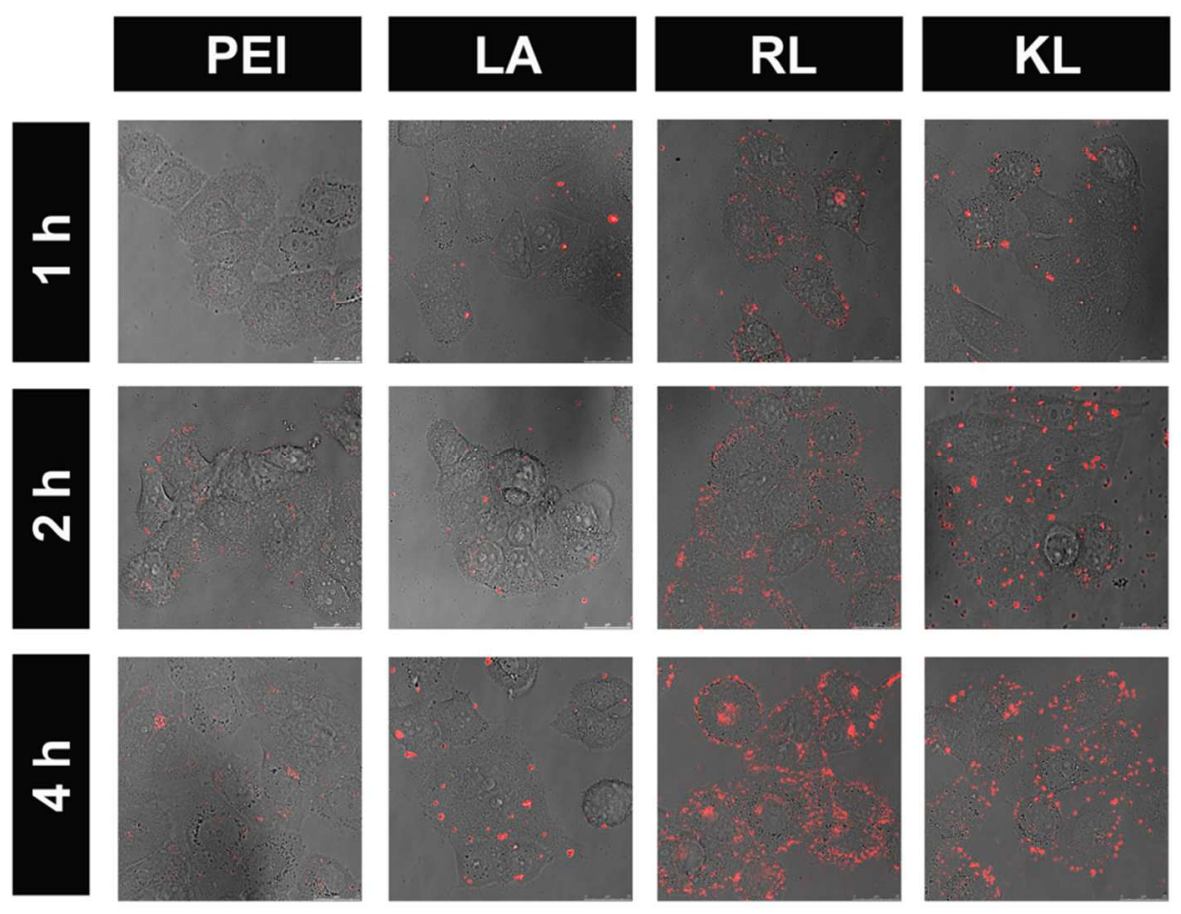

Figure S6. Cellular uptake image of gene complexes containing Cy5-labelled plasmid (Red) in HepG2 cells at different time points. 


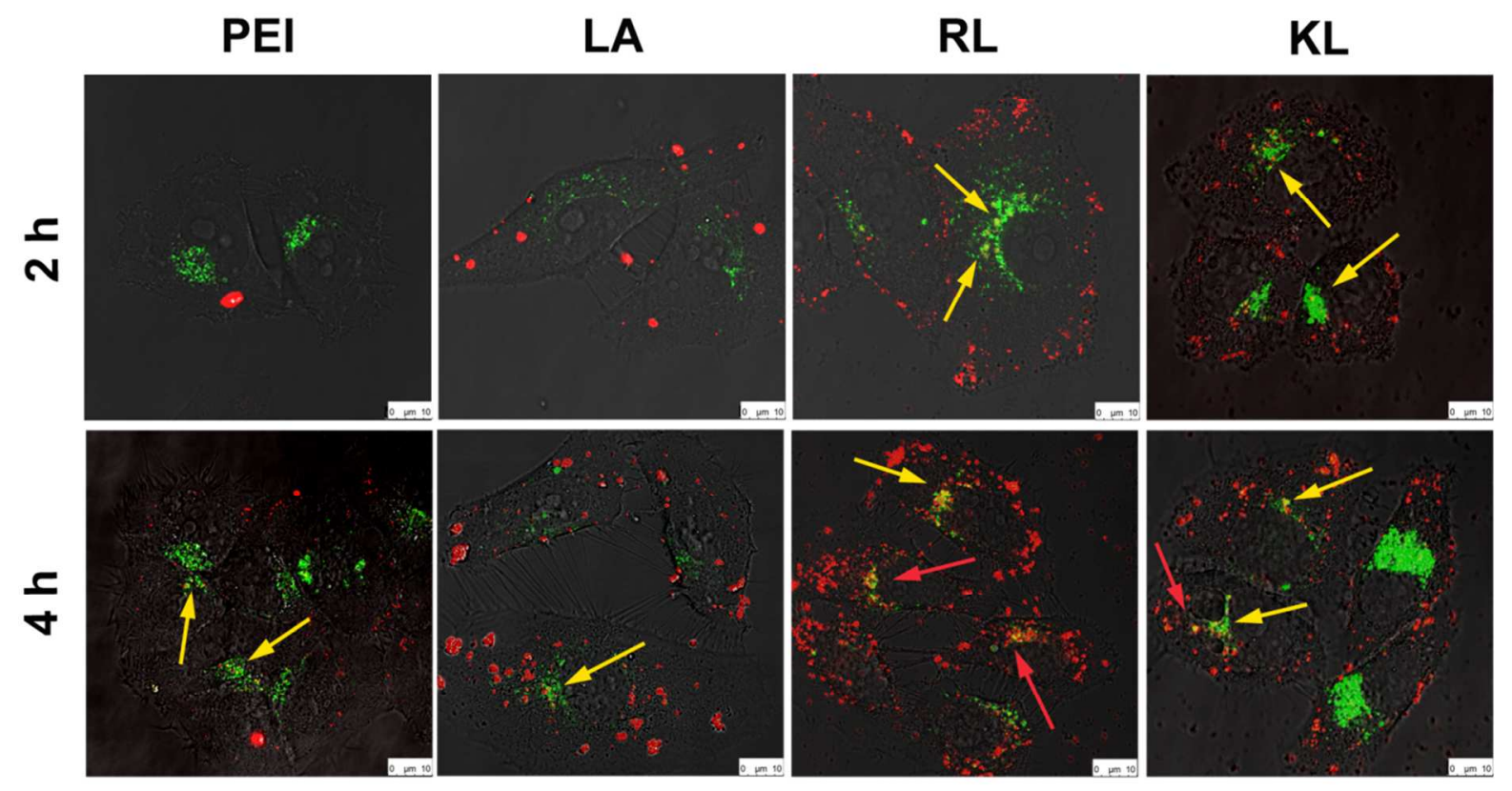

Figure S7. Image of endosomal disruption of gene complexes containing Cy5-labelled plasmid (Red) in cells with LysoTracker ${ }^{\mathrm{TM}}$ Green (Green) after $2 \mathrm{~h}$ and $4 \mathrm{~h}$ incubation. Yellow color indicated that the complexes encaged in lysosomes (as indicated by yellow arrows), and red meant successful endosomal disruption (as indicated by red arrows). 


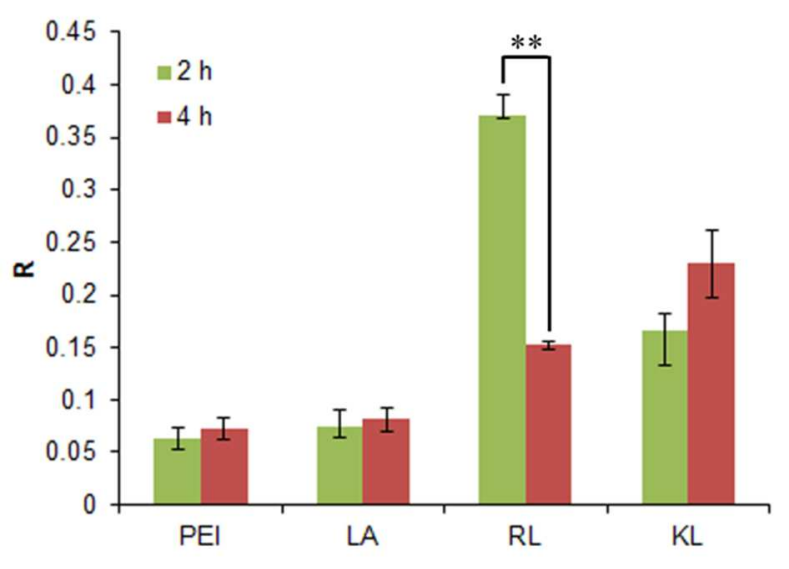

Figure S8. The colocalization ratio of red fluorescence of Cy5-labeled DNA with the green fluorescence of LysoTracker Green after cells were treated with different complexes for $2 \mathrm{~h}$ and 4 h. $* * p<0.01$ 